\title{
The Students' Perception on the Characteristics of Effective and Ineffective English Language Teachers
}

\author{
Khaerati \\ khaeratijafar@gmail.com \\ STKIP Pembangunan Indonesia Makassar, \\ Indonesia
}

\begin{abstract}
Effective and ineffective English teacher will determine the success of teaching and learning process. This research was conducted to find out the students' perception on the characteristics of effective and ineffective English language teachers. The methodology employed in this research was qualitative method by applying coding of qualitative data. The main instrument of this research was data in the form of essay. The essays were collected from the students. The data analysis was carried out by following the grounded theory procedure and technique comprised three steps: open coding (inductive), axial coding and selective coding. This research found out that there are several characteristics of effective and ineffective English teacher. They are teacher's personality, teacher's appearance, teacher's classroom performance, material mastery and classroom management.
\end{abstract}

Keywords: effective, ieneffective, perception

\section{INTRODUCTION}

Schools are one of the first places where students' behavior and future educational success are shaped. At schools there are many elements or factorsthat can influence the teaching and learning process may take place. There are four perennial truths that make the teaching and learning processes possible to take place in the classroom. If one of these is not available, there will be no teaching and learning process, though the learning process itself may still take place, they are:
a) Teacher
b) Students
c) Material
d) Context of time and place (Rasyid, 2012)

All of them are related to each other. Teachers have important role for the success of teaching and learning process. Teachers are carriers of either positive or negative behavior toward students. Students tend to copy the behavior and mannerism of the teachers. The teachers' entire personality is a reflection on the minds of the students. 
If the teacher is honest, leads a balanced and disciplined life, the children adopt these virtues as an ideal conduct unconsciously. The ideal teachers one who through their thoughts, words and deeds, gives and an impression of an honest upright life which can serve as a model for the students to copy, follow and emulate.

Therefore, the researcher believes the way students act depends on the teacher's attitude. It is very important that teachers encourage students because students will benefit from it. A teacher carries a big responsibility in her classroom. One reason is that all students depend on her/him. Everything the teacher says will have an impact on the students. If the teacher feels joy of feels anger, it will be spread among students because the attitudes of the teacher gets contagious. If the teacher laughs, students also laugh, because teachers are responsible for the social behavior in the classroom. If something goes wrong, the only responsible is the teachers even if it was not their fault.

Furthermore, it is sometimes realized that most of the students have problems with their teacher. Although, there will never be a perfect relationship between teacher and students, but as teacher, should build a good relationship with the students or even try to be an effective teacher for them. Despite all, a teacher should avoid some criteria that can categorize him to be an ineffective teacher.

\section{Research Questions}

This research attempts to answer the following research questions:

a. What are the students' perceptions on the characteristics of an effective Englishteacher?

b. What are the students' perceptions on the characteristics of an ineffectiveEnglish teacher?

\section{Objective of the Research}

The objective of the research is to describe the characteristics of an effective and ineffective English language teacher, so that the English teacher can have a broad and wide knowledge to follow to be an effective English language teacher as well as actions to avoid in order not to be an ineffective English language teacher. 
Khaerati : The Students' Perception on ...

$\mid 223$

Methodology of the Research

\subsection{Respondents}

The respondents of this research were the students of English Education Department that have experienced of having being taught by several kinds of English teachers. There were 20 respondents grouped into two groups to answer two different kinds of questions.

\subsection{Method, Instrument and Procedure}

This research employed qualitative method by applying coding of qualitative data. The main instrument of this research was data in the form of essay. The essays were collected from the students. The data analysis was carried out by following the grounded theory procedure and technique comprised three steps: open coding, axial coding and selective coding.

\section{Definitions of keys terms}

\subsection{Coding}

Coding is the process of examining the raw qualitative data which will in the form of words, phrases, sentences or paragraphs) and assigning CODES or labels. Strauss and Corbin (1990) identified the following types of coding: Axial coding and Open Coding.

\subsection{Open Coding}

We "sweep" through the data and mark (by circling or highlighting) sections of the text selected codes or labels. For example, we circle words or phrases describing the behaviour of the head of department.

\subsection{Axial Coding}

Eventually, we have a large number of codes and you will find it necessary to sort them into some sort of order or into groups and this is called axial coding. Two common types of axial coding are: Non-hierarchical or Hierarchical.

Non-Hierarchical: For example, in a study, the researcher asked a group of adults how they take a break from their normal work. The responses are grouped as follows in a non-hierarchical manner (also called flat coding). Hierarchical: Here we can find that several codes group together as types or kinds of something. we need to put some of the codes or labels into a group of their own or make them sub-codes, i.e. a hierarchical arrangement of codes, like a tree, a branching arrangement of sub-codes. Ideally, codes in a tree relate to their parents by being 'examples of...', or 'contexts for...' or 'causes of...' or 'settings for...' and so on. For example, a researcher was doing a study on friendship ${ }^{\text {ee }}$ and asked a group of adults their views on the topic. 
Open Coding is generally the initial stage of Qualitative Data Analysis. After completing the Open Coding, depending on the methodology we use, we can do Axial Coding and Selective Coding. At later stage of the research, these coding help us to build theories in an inductive process (i.e. Grounded Theory). Open Coding can be used with inductive, deductive or verification modes of inquiry too.

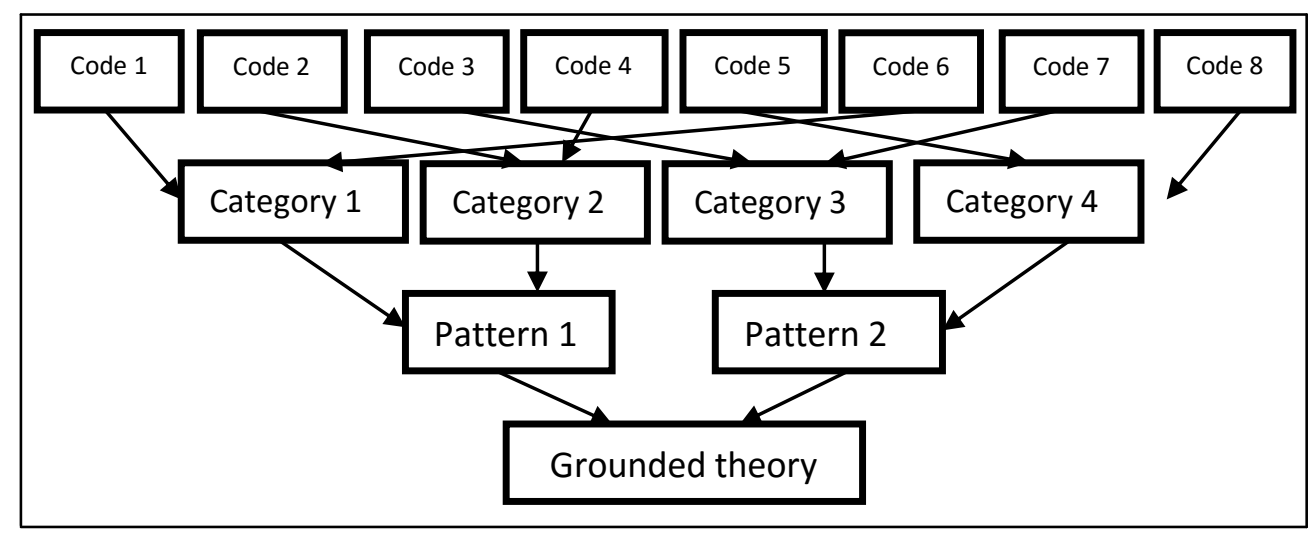

Workflow of Grounded Theory Methodology

\section{Review of Related Literature}

Anton Lee (2003) found out that there are five key factors that provide a foundation for a good teaching: (a) Teacher knowledge, enthusiasm and responsibility for learning, (b). Classroom activities that encourage learning, (c) Assessment activities that encourage learning through experience, (d) Effective feedback that establishes the learning processes in the classroom, (e) Effective interaction between the teacher and the students, creating an environment that respects, encourages and stimulates learning through experience.

AlSeweed (2012) conducted a research and showed the results that there were reveal statistical significant difference in the participants' perceptions in favor of Native English Speaker Teachers (NESTs). Students showed more preference for NESTs as they go to higher levels. Students' previous learning experiences may affect their general preference for NESTs since they were taught by both types of teachers. Subjects also exhibited an explicit preference for NESTs in relation to the teaching strategies adopted. However, the participants showed moderately favorable attitudes towards Non Native English Speaker Teachers (NNESTs) who provide a serious learning environment and a favorable response to learners' needs. All teachers do good things some of the time, and all good teachersdo bad things some of the time. The differences among teachers lienot only in the proportions of the good and the bad, but also in theirawareness of the effects of what they are doing and their readinessto share this awareness with their students (Smith, 1995: 590) 
Khaerati : The Students' Perception on ... $\mid 225$

From the above previous findings, the researcher tries to find out the students' perception on the characteristics of effective and ineffective English Language teachers.

\section{Findings and Discussions}

a. The data of an effective teacher is categorized into the following:

1) Teacher's Personality :

1. Pleasing

2. Giving attention to her students

3. Loving her job

4. Being Funny

5. Being an Understandable person

6. Being calm

7. Being helpful

8. Being closed to the students

9. Being honest

10. Being self-confident

11. Being not conceited

12. Being courteous to his colleagues

13. Not easy to get angry

14. Kind

15. Being discipline

16. Being a nice person

17. Not merely easy to be angry

18. Patient

19. Responsible

20. Having a good attitude

21. Being friendly

22. Being strict

23. Having a warm personality

24. Being Perfect

\section{Teaching Performance :}

- Mastery of material :

1. Not merely using text book

- Teaching method :

1. Not using old method

2. Demonstrating experiments

3. Showing authentic material 
226| ELT Worldwide Vol. 3 No.2 October 2016

4. Showing picture of the object

5. Changing complicated subject into the fun one

6. Formulating interesting techniques

7. Encouraging the students to speak English

8. No language except English

9. Explaining the lesson accurately

10. Asking the students to find the difficult words

11. The teaching techniques were interesting

12. Giving some English songs

13. Giving common expressions to the students before class over.

- The way treating the students :

1. Knowing how to appreciate the students

2. Building the students' spirit

3. Giving reward (money etc.)

4. Motivating the students

5. Treating students like friends

6. Never shouted

7. Not Making the students feeling nervous

8. Supporting the students

9. Encouraging the students

10. Calling the students with " honey or baby"

\section{- Classroom management :}

1. Making classroom funny and comfortable

2. Creating enjoyable and relaxed class

3. Solving the problem easily and effectively

4. Applying many kinds of games

5. Bringing the students to study outside the classroom

2) Teacher's Competence/ Professionalism :

1. Having in-depth knowledge about the subject/material

2. Brilliant

3. Having a wonderful ability

4. Being Smart

5. Teaching the right answer

6. Can speak many languages

3) Teacher's Appearance :

1. Handsome

2. Cute hair cut

3. Pointed nose 
4. Smiling face

5. Good looking

6. Having a clean skin

7. Being neat

From the data above, the following principles were taken out from the deep analysis in the form of essay for considering the characteristics of effective English language teacher as follow:

1. Having a good and pleasant personality that can make and create a good relationship with the students to have the material easily and comfortably. An effective teacheralso celebrates his/her students 'success by praising them.

2. Showing an appropriate teaching performance that includes teaching method, material mastery, and teacher's behavior toward the material and classroom management to cover all the students' need in order to encourage the students to have a higher achievement of the subject. A good teacher should be able to consider the needs of the students and then decide on the right approach to be used in his/her classes.

3. Showing a good appearance, does not always mean that the teacher should be beautiful or handsome, but he should show a nice looking to his students.

b. The data of an ineffective teacher is categorized into the following:

1) Unacceptable Personality :

1. Unfair

2. Boring and annoying

3. Bad tempered

4. Scary

5. Unfriendly

6. Lazy

7. Having a bad attitude

8. Cheating

9. Like to take revenge

10. Like to tell the students' weakness to others

11. Indiscipline

12. Absent for the class without any information

2) Unacceptable Performance in the classroom :

- The bad way in treating the students :

1. Not answering the students' question

2. Judging the students by saying "stupid" 
228| ELT Worldwide Vol. 3 No.2 October 2016

3. Scolding the students

4. Not like to be asked about the material

5. Refusing to be corrected

6. Not realizing his mistakes

7. Only like/ focus on the smart students

8. not caring about the students' misbehaviors

9. Expressing bad utterances/ expressions

10. Making the students feel terribly insecure

11. Always sitting behind the desk in classroom

12. Bringing forward the personal problems into the classroom

13. Making the students as objects of anger

14. Telling all about his richness

15. Sleeping after giving a test/exam to the students

\section{- Actions concerning with the teaching method :}

1. Giving assignment without explanation before

2. Boring teaching method

3. No jokes/refreshment in the classroom

4. No chance for students to speak

5. Bad teaching method

6. Causing the students to become lazier

7. No discussion for the given assignment

8. Never check the students' assignment

9. Always giving dictation to the students

10. Using Indonesian Language

11. Asking the students to do the task in the text book all the time/ every meeting

12. Never giving the students something special

13. Always teaching in the classroom, never bringing out the students outside

14. No games

15. The class environment becomes dull

16. Unwilling to explain the lesson/ material

17. Giving too many assignments

18. Teaching a complicated theory

19. Too fast in explaining the material

20. Using the same method all the time/ every meeting

21. Always asking the students to translate 


\section{- Bad model for the students to follow :}

1. Coming late to the class

2. Selling copy of material to the students

\section{3) Incompetence :}

\section{- Mastery of material :}

1. Unable to answer the students' questions

2. The explanation is confusing

3. Weak competence/ incompetence

4. Lack of creativity

5. Always focusing on the text book

6. Unprepared lesson

7. Not knowing what to teach/ not mastering the material

\section{- Classroom management :}

1. Getting busy with herself, without considering the students' need.

2. Creating a boring class

3. Lack of intrapersonal intelligence

4. Less attention to his students

5. Not knowing the students' background

4) Unacceptable Appearances :

1. Being Slipshod and dirty

2. Not Dressing neatly and cluttered

From the data above, the following principles were taken out from the deep analysis in the form of essay for considering the characteristics of ineffective English language teacher as follow:

1. Having unacceptable personalities that can lead the teacher to the problem with the students.

2. Incompetence, this includes material mastery and classroom management. If a teacher feels lack of these two elements, it is suggested to have more training. Because these arethe most important thing in teaching, how a teacher can manage the class, if he is poor in the classroom management as well as material mastery, of course he cannot teach well if he does not know what to teach.

3. Having unacceptable or bad appearances. An English teacher should always show the good appearance, because if he has bad appearance, it will attract the students' concentration on judging their teacher. 


\section{Conclusions}

The students' perception on the characteristics of effective and ineffective English language teacher may vary, when thinking of an effective EFL teacher in general, one may list a number of features of characteristics. These characteristics can be sorted in a more specific manner when listing the qualities of an effective EFL teacher. As a matter of fact, the characteristics of an effective teacher will determine the success of teaching and learning process.

\section{Suggestion}

It is suggested for the further research to have a deep investigation on students' perception on effective and ineffective English language teachers by having different respondents to have more variable data.

\section{References}

Alton-Lee, A. 2003. Quality teaching for diverse students in schooling: Best evidence synthesis. Wellington: Ministry of Education.

Khandkar, ShahedulHuq. Online.http://pages.cpsc.ucalgary.ca/ saul/wiki/uploads/CPSC681/ open-coding.pdf

Rasyid, Muhammad Amin. 2012. Presentation.

Smith, F. 1995. Let's declare education a disaster and get on with our lives. Phi Delta Kappan, 76, 584-590.

Strauss, A. and Corbin, J. 1990. Basics of qualitative research: Grounded theory procedures and techniques. London: Sage.Online. 